\title{
Arabino-mycolates derived from cell-wall skeleton of Mycobacterium bovis BCG as a prominent structure for recognition by host immunity
}

\author{
Masanori Miyauchi ${ }^{1, *}$, Masashi Murata ${ }^{1}$, Keiko Shibuya ${ }^{1}$, Erina Koga-Yamakawa ${ }^{1}$ Yuko Uenishi ${ }^{2}$, \\ Naoto Kusunose', Makoto Sunagawa ${ }^{2}$, Ikuya Yano ${ }^{3}$, Yasuo Kashiwazaki ${ }^{1}$ \\ ${ }^{1}$ Drug Research Division, Dainippon Sumitomo Pharma Co., Ltd., Osaka, Japan; \\ ${ }^{2}$ Technology Research \& Development Division, Dainippon Sumitomo Pharma Co., Ltd., Osaka, Japan; \\ 3 Japan BCG Central Laboratory, Tokyo, Japan.
}

\begin{abstract}
Arabino-mycolates are components of the cell-wall skeleton of Mycobacterium bovis BCG (BCG-CWS). It is known that synthesized arabinomycolates induce the production of tumor necrosis factor alpha (TNF- $\alpha$ ) in murine macrophage cell lines at an intensity similar to that of BCG-CWS. However the immunological activity of natural arabino-mycolates isolated from BCG has not been investigated, probably due to the complexity of the molecule. In this paper, we investigated the immunostimulatory activity of arabino-mycolates isolated from BCG-CWS by acid hydrolysis. Arabino-mycolates obtained by acid hydrolysis from the originally prepared CWS (SMP-105) of $M$. bovis BCG Tokyo 172 strain consisted mainly of mono-arabinose mono-mycolate, pentaarabinose tetra-mycolate and hexa-arabinose tetramycolate fractions. Arabino-mycolates significantly induced TNF- $\alpha$ production with an intensity comparable to that of CWS and enhanced delayed type hypersensitivity (DTH) reactions against inactivated tumor cells. Arabino-mycolates-induced TNF- $\alpha$ production was completely dependent on TLR2 and MyD88 pathways. These findings indicate that isolated natural arabino-mycolates possess potent adjuvant immunostimulatory activity.
\end{abstract}

Keywords: Arabino-mycolates, TLR2, BCG-CWS, SMP-105

\footnotetext{
*Address correspondence to:

Dr. Masanori Miyauchi, Drug Research Division, Dainippon Sumitomo Pharma Co., Ltd., 3-1-98, Kasugade-naka, Konohana-ku, Osaka-shi, Osaka, 554-0022, Japan.

e-mail: masanori-miyauchi@ds-pharma.co.jp
}

\section{Introduction}

The cell-wall skeleton (CWS) of Mycobacterium bovis BCG (BCG-CWS), a microbial adjuvant, has intensively been investigated for decades, and has consequently been shown to possess promising activity as a cancer immunotherapeutic agent (1-4). Toll-like receptors (TLRs) have been characterized as pattern-recognition receptors that recognize microbial components $(5,6)$. Stimulation of macrophages and dendritic cells via TLRs induces production of cytokines and chemokines, and creates bridges to establish acquired immunity. Recent studies suggest that BCG-CWS induces cytokines and antitumor activity through TLR2 $(7,8)$. However, due to the complexity of BCG-CWS, it is not clear which motif is essential for stimulating immunity or TLR2 agonistic activity.

BCG-CWS has a high molecular weight and is reported to be a mycoloyl-arabinogalactan-peptidoglycan complex. We have tried to shed light on the arabinomycolate moiety of BCG-CWS and analyze its structure and biological activity. GC-MS and NMR of cell wall arabinogalactan oligosaccharide fragments revealed that the arabinogalactan contains a homogalactan segment of alternating 5-linked $\alpha$-galactofuranosyl (Galf) and 6-linked $\beta-\mathrm{Gal} f$ residues, and arabinan segments consisting of two major domains: a linear 5-linked arabinofuranosyl $(\alpha$-Ara $f$ ) unit with branching introduced by 3,5- $\alpha$-Ara $f$ and branched oligosaccharides $[\beta \text {-Araf-(1-2)-Araf }]_{2}-$ 3,5- $\alpha$-Ara $f$ at the nonreducing termini (9). Separately, synthesized mycolic esters of the arabinan in the terminal lipo-arabinan motif have been shown to induce production of TNF- $\alpha$ (10). Although some glycolipids that do not constitute BCG-CWS, such as trehalose 6,6'-dimycolate (TDM), lipoarabinomannans, and phosphatidylinositol mannosides, have energetically been studied (11-15), arabino-mycolates that constitute BCG-CWS have not been investigated. We therefore were interested in isolating BCG-CWS arabino-mycolates and investigating their structural properties and immunostimulatory activity. Uenishi et al. have developed a unique method 
for isolation of arabino-mycolates derived from the cellwall skeleton of M. bovis BCG Tokyo (SMP-105) (16). By making use of this method, particularly the isolated fraction consisting mainly of mono-arabinose monomycolate, tetra-arabinose tetra-mycolate, penta-arabinose tetra-mycolate and hexa-arabinose tetra-mycolate (Figure 1), we proceeded with our structural and biological investigation of BCG-CWS arabino-mycolates.

In this paper, we demonstrate that arabino-mycolates isolated from CWS activate macrophages via the TLR2MyD88 pathway in vitro and have potent adjuvant activity in vivo. The mechanism of cell-mediated immunity activation by a giant insoluble BCG-CWS will be addressed in the context of digestive degradation reported in our previous paper (17).

\section{Materials and Methods}

\subsection{Preparation of cell-wall skeleton (CWS) and arabino- mycolates}

CWS (SMP-105) was prepared from M. bovis BCG Tokyo 172 strain as previously described (18), and arabino-mycolates were isolated as indicated elsewhere (16). In brief, a CWS suspension in toluene $/ 0.1 \mathrm{~mol} /$ $\mathrm{L}$ hydrochloric acid $(1: 1, \mathrm{v} / \mathrm{v})$ was heated at $100^{\circ} \mathrm{C}$ for about 1.5 hours. The toluene layer, taken as the portion containing the arabino-mycolates was washed with water and then evaporated. The residual arabino-

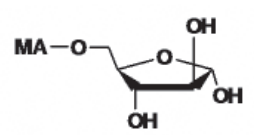

mono-arabinose mono-mycolate

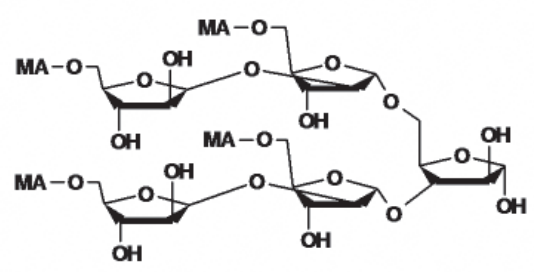

penta-arabinose tetra-mycolate

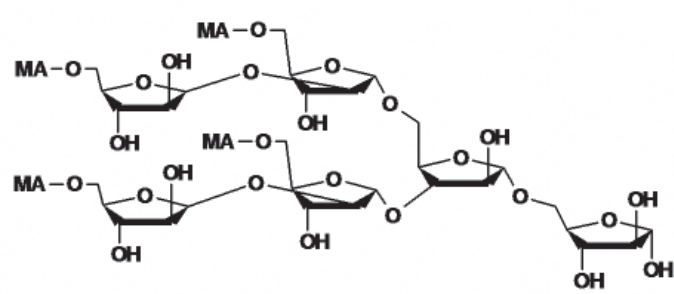

hexa-arabinose tetra-mycolate

Figure 1. Structure of arabino-mycolate fragments obtained from CWS of $M$. bovis BCG Tokyo 172. MA, micolic acid. mycolates were developed on silica gel HPTLC (Silica gel 60, $10 \times 10$ cm, Merck Ltd., Darmstadt, Germany) with a solvent containing chloroform/acetone/acetic $\mathrm{acid} / \mathrm{methanol}(90: 6: 1: 10, \mathrm{v} / \mathrm{v})$ for further purification, which revealed multiple spots. The major spots, called A, B, B1, C and D, were deduced to be penta-arabinose tetra-mycolate, hexa-arabinose tetra-mycolate, mono-arabinose mono-mycolate, hepta-arabinose tatra-mycolate, and octa-arabinose tetra-mycolate, respectively. The $\mathrm{A}, \mathrm{B}$ and $\mathrm{B} 1$ spots were selected as arabino-mycolates for investigation of biological activity. The yield of refined arabino-mycolates was approximately $17.9 \%$.

\subsection{Trehalose 6,6'-dimycolate (TDM)}

TDM was prepared as described previously (4). In brief, lipids were extracted from heat-killed M. bovis BCG Tokyo 172 strain with chloroform/methanol (2:1, v/v). After the lower phase of two phases containing major glycolipids was collected, the solvent was evaporated in a rotary evaporator. Total lipids were then separated by thin-layer chromatography (TLC) on silica plates (Uniplate; Analtech, DE, USA), and TDM was recovered from the plate immediately after the iodine color had disappeared by passing through a small glass column. TDM was further purified by repeated TLC until a single spot was obtained.

\subsection{Reagents}

Pam3CSK4 was purchased from Calbiochem (Merck, Tokyo, Japan). Escherichia coli J5 lipopolysaccharide (LPS) was purchased from LIST Biological Laboratories (Campbell, CA, USA), and further purified using a phenol extraction method (19-21).

\subsection{Animals}

C57BL/6J female mice were purchased from Japan SLC (Shizuoka, Japan). TLR2 (22)-,TLR4 (23)- and MyD88 (24)-deficient mice were obtained from Oriental Bio Service (Kyoto, Japan). All mice were maintained under specific pathogen-free conditions. All animal experiments were conducted according to the guidelines of the Animal Care and Use Committee at Dainippon Sumitomo Pharma.

\subsection{Cell lines}

Murine macrophage cell line RAW264.7 was purchased from American Type Culture Collection (Manassas, VA, USA), and was maintained in DMEM (SigmaAldrich, MO, USA) supplemented with $10 \%$ FCS, 2 $\mathrm{mM}$ L-glutamine, $50 \mathrm{U} / \mathrm{mL}$ of penicillin, and $50 \mu \mathrm{g} / \mathrm{mL}$ of streptomycin. Lewis lung carcinoma (3LL) was obtained from the Cancer Institute for the Japanese 
Foundation for Cancer Research (Tokyo, Japan). 3LL cells were maintained in RPMI-1640 medium supplemented with $10 \%$ fetal calf serum (FCS), 50 $\mu \mathrm{g} / \mathrm{mL}$ of streptomycin, and $50 \mathrm{U} / \mathrm{mL}$ of penicillin. To prepare inactivated $3 \mathrm{LL}, 3 \mathrm{LL}$ cells were incubated at $37^{\circ} \mathrm{C}$ for $20 \mathrm{~min}$ at $1 \times 10^{7}$ cells $/ \mathrm{mL}$ in a culture medium containing $200 \mu \mathrm{g} / \mathrm{mL}$ of mitomycin C (Kyowa Hakko Kogyo, Tokyo, Japan), followed by repeated washing with sufficient culture medium.

\subsection{Preparation of mouse peritoneal exudate cells}

Thioglycollate-elicited peritoneal exudate cells (TG-PEC) were prepared from mice 5 days after intraperitoneal injection of 3\% thioglycollate medium (Difco; Becton Dickinson Japan, Tokyo, Japan), and seeded at $5 \times 10^{5}$ cells/well in a 96-well plate. After removal of nonadherent cells by washing, adherent macrophages were treated with $1 \mathrm{ng} / \mathrm{mL}$ of recombinant mouse IFN- $\gamma(\mathrm{R} \& \mathrm{D}$ Systems, MN, USA) for 2 hours.

\subsection{TNF- $\alpha$ induction assay}

For experiments using RAW264.7 cells, CWS and arabino-mycolates were suspended in hexane/ethanol (9:1, v/v) and dispensed into 96-well polypropylene microplates before the solvent was evaporated in a clean bench. RAW264.7 cells were then seeded at $5 \times 10^{4}$ cells/well and cultured overnight.

For TG-PEC, a suspension of CWS or arabinomycolates was prepared in saline containing $0.01 \%$ polysorbate 80 using a Potter-type homogenizer at 1,200 rpm for $5 \mathrm{~min}$. TG-PEC was cultured overnight with the suspension of CWS or arabino-mycolates. The concentrations of TNF- $\alpha$ in the supernatants were determined by enzyme-linked immunosorbent assay (ELISA) (R\&D Systems; Minneapolis, MN, USA).

\subsection{Delayed type hypersensitivity (DTH) reaction}

Inactivated $3 \mathrm{LL}$ cells $\left(3 \times 10^{4}\right.$ cells $)$ in an oilin water emulsion of vehicle, CWS $(12.5 \mu \mathrm{g})$, or arabinomycolates $(12.5 \mu \mathrm{g})$ were intradermally administered twice with a 7-day interval between injections into the left flank region of $\mathrm{C} 57 \mathrm{BL} / 6 \mathrm{~J}$ mice.

Seven days after the second administration, inactivated 3LL cells ( $10^{5}$ cells in $50 \mu \mathrm{L}$ Hanks' Balanced Salt Solution) were inoculated into the left hind footpads of mice. Just before and 24 hours after inoculation, the thickness of the left footpad was measured using a dial gauge (Mitsutoyo Corp., Kanagawa, Japan). Percentage swelling of the footpad was calculated according to the following equation:

Footpad swelling $(\%)=($ thickness of post-injected footpad (mm) - thickness of pre-injected footpad ( $\mathrm{mm})$ )/ thickness of pre-injected footpad (mm)
The emulsion was prepared as follows; A four hundred micro liter aliquot of CWS or arabino-mycolates suspension dispersed in chloroform at $2 \mathrm{mg} / \mathrm{mL}$ was taken in a Potter-type homogenizer and $5.7 \mu \mathrm{L}$ of squalane was added, followed by evaporation of the chloroform. Next, $0.66 \mathrm{~mL}$ of $5.1 \%(\mathrm{w} / \mathrm{v})$ mannitol solution containing $1 \%$ (w/v) polysorbate 80 was added, and the mixture was homogenized at 2,000 rpm for 10 min with a Potter-type homogenizer. The composition of the vehicle was the same except for CWS or arabino-mycolates.

\subsection{Statistical analysis}

Results from all experiments are expressed as mean \pm standard deviation (S.D.). Significant differences in DTH reaction were assessed using Dunnett's multiple comparison. Statistical analyses were carried out using SAS software (SAS Institute; Cary, NC, USA).

\section{Results}

\subsection{Arabino-mycolates induce production of TNF- $\alpha$ in RAW264.7 cells}

To confirm that arabino-mycolates activate macrophages, we investigated the ability of arabino-mycolates isolated from CWS to induce TNF- $\alpha$ production in RAW264.7 cells. Arabino-mycolates dose-dependently induced TNF- $\alpha$ production in RAW264.7 cells with an intensity similar to that of CWS (Figure 2a). This finding indicates

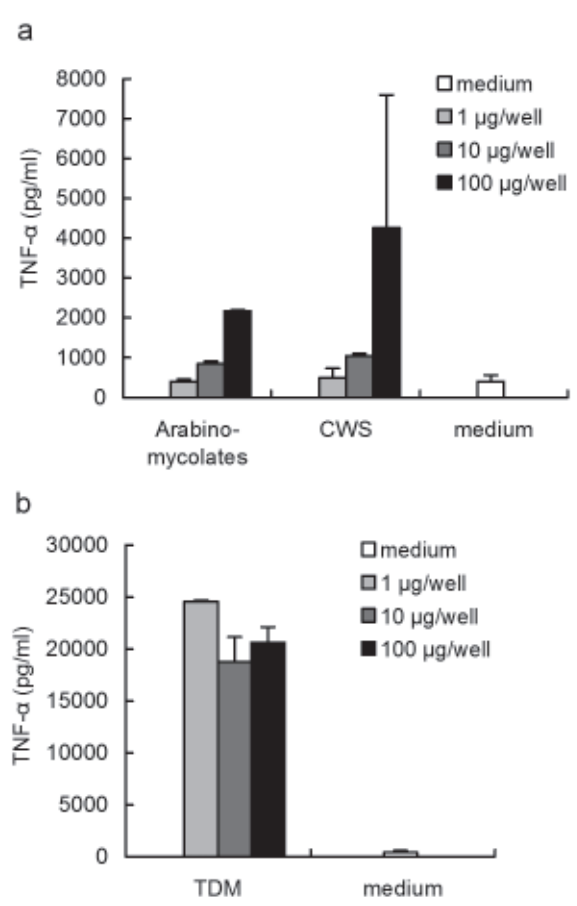

Figure 2. CWS and arabino-mycolates induced production of TNF- $\alpha$ in RAW264.7 cells. RAW264.7 cells were cultured in microplates absorbing CWS or arabino-mycolates (a) or TDM (b) overnight. TNF- $\alpha$ in the supernatant was determined by ELISA. Values are expressed as the means \pm S.D. of triplicate determinations. 
that arabino-mycolates stimulate innate immunity. Like CWS and arabino-mycolates, TDM, a mycolic ester of saccharides contained in the cell wall of mycobacteria, also induced TNF- $\alpha$ production in RAW264.7 cells (Figure 2b). The amount of TNF- $\alpha$ induced by TDM was greater than that induced by CWS or arabino-mycolates.

\subsection{Arabino-mycolates activate TG-PEC in a TLR-2- dependent manner}

To evaluate the effects of arabino-mycolates on TLRs, we next examined the ability of TG-PECs derived from TLR2, TLR4, or MyD88 knockout mice to induce TNF- $\alpha$ production. CWS and Pam3CSK4 (two TLR2 agonists), and LPS (a TLR4 agonist) were used as controls. As expected, CWS and Pam3CSK4 induced TNF- $\alpha$ production in TG-PEC derived from WT and TLR4 knockout mice, but not in TG-PEC derived from TLR2 or MyD88 knockout mice. LPS on the other hand induced TNF- $\alpha$ production in TG-PEC derived from WT and TLR2 knockout mice, but not in TGPEC derived from TLR4 or MyD88 knockout mice. As in RAW264.7 cells, arabino-mycolates induced TNF- $\alpha$ production in TG-PEC derived from wild type mice, but not in TG-PEC derived from TLR2 or MyD88 knockout mice (Figure 3). Arabino-mycolates also induced TNF- $\alpha$ production in TG-PEC derived from TLR4 knockout mice with an intensity comparable to that found in wild type mice. These results indicate that the mycolylarabinan structure activates TG-PEC in a TLR-2-/ MyD88- dependent manner.

\subsection{Arabino-mycolates enhance a DTH reaction}

We next evaluated the ability of arabino-mycolates to stimulate innate immunity using a DTH reaction

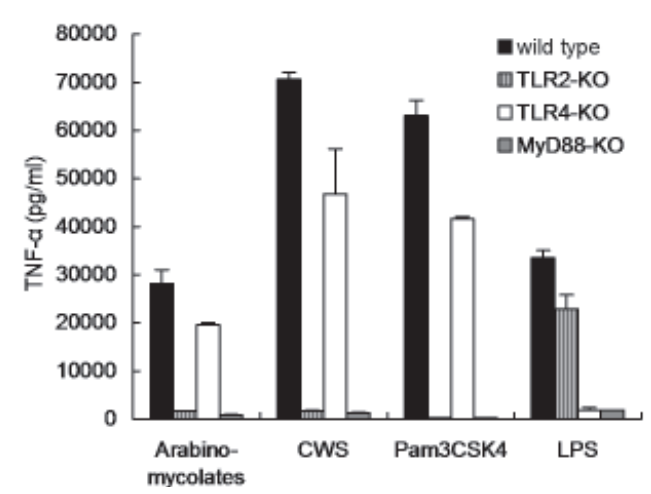

Figure 3. Arabino-mycolates induced production of TNF- $\alpha$ in TG-PEC derived from different mice. TG-PEC derived from wild type mice (black bar), TLR2 knockout (KO) mice (vertical stripes), TLR 4 KO mice (white bar), or MyD88 KO mice (gray bar) were cultured in the presence of $1 \mathrm{ng} / \mathrm{mL}$ of recombinant mouse interferon- $\gamma$ with a medium control, CWS (100 $\mu \mathrm{g} / \mathrm{mL})$, arabino-mycolates (100 $\mu \mathrm{g} / \mathrm{mL})$, Pam3CSK4 (1 $\mu \mathrm{g} / \mathrm{mL})$ or LPS $(1 \mu \mathrm{g} / \mathrm{mL})$. After 18 hours, each supernatant was collected and the concentration of TNF- $\alpha$ was determined by ELISA. Values are expressed as the means \pm S.D. of triplicate determinations. in mice. C57BL/6J mice were twice (once weekly) sensitized with mitomycin Ctreated 3LL tumor cells as antigen and CWS or arabino-mycolates as adjuvant. The mice were elicited one week after the 2 nd sensitization by administration of the antigen only into the hind footpad. The DTH reaction was accessed by footpad swelling 24 hours after elicitation. CWS significantly enhanced the DTH reaction in mice (Figure 4). Arabinomycolates on the other hand moderately enhanced DTH, which was significantly evoked with the vehicle. These findings indicate that arabino-mycolates induce establishment of $\mathrm{T}$ cell immunity. We think that the DTH results are consistent with the results of arabinomycolates induction of TNF- $\alpha$ production in vitro.

\section{Discussion}

To our knowledge, this study is the first to demonstrate the immunostimulatory activity of arabino-mycolates isolated from CWS, although CWS itself has previously been reported to induce TNF- $\alpha$ in murine TG-PEC (8), and synthesized arabino-mycolates have been shown to induce TNF- $\alpha$ in RAW264.7 cells (10). Using a recently reported method for isolation of mycolic esters of arabinan $(10,16)$, we isolated fractions containing the mono-arabinose mono-mycolate, penta-arabinose tetramycolate, and hexa-arabinose tetra-mycolate (Figure 1) and used them to investigate arabino-mycolates immunological activity. We found that arabinomycolates activate macrophages via the TLR2-MyD88 pathway in vitro, and possess potent adjuvant activity in a DTH model.

Arabino-mycolates induced TNF- $\alpha$ production in RAW264.7 cells with an intensity similar to that of

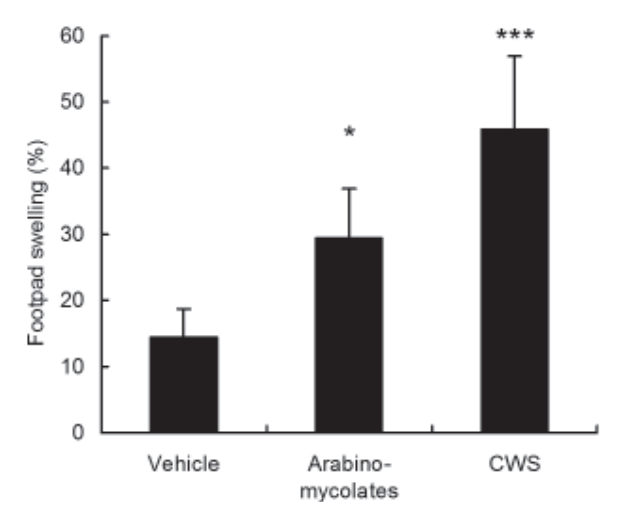

Figure 4. Effects of arabino-mycolates from CWS on delayed-type hypersensitivity reaction against $3 \mathrm{LL}$ tumor cells. Inactivated $3 \mathrm{LL}$ cells $\left(3 \times 10^{4}\right.$ cells $)$ in an oilin water emulsion of vehicle, CWS $(12.5 \mu \mathrm{g})$ or arabino-mycolates $(12.5 \mu \mathrm{g})$ were intradermally administered twice with a 7-day interval between injections into the left flank region of C57BL/6J mice. Seven days after the second administration, inactivated $3 \mathrm{LL}$ cells $\left(10^{5}\right.$ cells $)$ were inoculated into the left footpads and swelling was monitored by measuring the thickness of the footpads 24 hours after inoculation, ${ }^{*} p<$ 0.05 ; ${ }^{* * *} p<0.001$ (parametric Dunnett's test for multiple comparisons; compared to vehicle). Values are expressed as the means \pm S.D. of six mice. 
CWS. This finding indicates that arabino-mycolates stimulate innate immunity (Figure 2a). Uenishi et al. have shown that CWS from M. bovis BCG Tokyo 172 contains $38.8 \%$ mycolic acid and $23.0 \%$ arabinose (18). Considering that the mycolate and arabinose constitute over half of the CWS, the amount of TNF- $\alpha$ produced by CWS seems to be consistent with the arabino-mycolate moiety.

We have previously reported that CWS activates the immune response in a TLR2-/MyD88- dependent manner (8). Accordingly, in this study arabino-mycolates induced TNF- $\alpha$ production in RAW264.7 cells as well as in TGPEC derived from wild type mice, but not in TG-PEC derived from TLR2 or MyD88 knockout mice (Figure 3). In addition, and as expected, arabino-mycolates induced TNF- $\alpha$ production in TG-PEC derived from TLR 4 knockout mice with an intensity comparable to that in wild type mice. Because neither mycolate nor arabinose can induce production of TNF- $\alpha$ (10), we postulate the mono-arabinose mono-mycolate as the smallest binding motif for TLR2. It is also likely that TLR2 dimerizes with different TLRs, i.e. TLR1 or TLR6, to recognize arabinomycolates $(25,26)$. Therefore, it is believed that the linkage region between mycolate- and arabinose-residues constitutes a crucial structure for binding to TLR2, which may render a plausible explanation as to why TDM is not recognized by TLR2 in spite of its similar structure to arabino-mycolates (27-29). Recently Ishikawa et al. have shown that macrophage inducible C-type lectin (Mincle) is an essential receptor for TDM in Mincle-deficient mice (30). Thus, the different signaling between arabinomycolates and TDM can explain the difference of the amount of TNF- $\alpha$ induced (Figures $2 \mathrm{a}$ and $2 \mathrm{~b}$ ).

There is a commonly-held view that TLR agonists affect antigen-presenting cells by inducing an innate immune response and subsequently activating the adaptive immune system. In addition a number of studies have shown that stimulation of innate immunity with CWS and TDM leads to establishment of antigenspecific T cell immunity by the DTH reaction $(17,31)$. We accessed in this study arabino-mycolate activity and used CWS as a control for the DTH reaction. Our results show that arabino-mycolates evoke significant swelling of the footpad (Figure 4). The swelling of footpad induced by CWS was also significant and almost comparable to that induced by arabino-mycoclates. There is so far no report showing that isolated natural arabino-mycolates stimulate innate immunity in vivo, although synthesized arabino-mycolates have been shown to induce TNF- $\alpha$ production in RAW264.7 cells in vitro (10). In this study, we show for the first time that isolated natural arabino-mycolates stimulate innate immunity in vivo. This finding indicates that arabinomycolate structure is important as it has a direct effect on adjuvant activity in CWS.

In this study, we show that arabino-mycolates stimulate macrophages to produce TNF- $\alpha$ and that this effect is dependent on the TLR2-MyD88 pathway in vitro. We also show that arabino-mycolates enhance establishment of $\mathrm{T}$ cell-mediated immunity in vivo. We have previously reported that CWS is engulfed into dendrtitic cells and distributed in lysozomes, and that activation of dendritic cells is blocked by inhibition of phagocytosis, addressing digestive fragments of CWS that may function as TLR2 ligands (17). Now that we have shown that arabino-mycolate fragments prepared by acid hydrolysis can stimulate TLR2, it is highly likely that CWS is engulfed by phagocytosis and transferred into lysozomes that undergo acid hydrolysis by digestive enzymes to produce fragments capable of interacting with TLR2 directly.

In conclusion, arabino-mycolates produced by acid hydrolysis of BCG-CWS have been shown to have potent TLR2 ligand activity and to constitute an important antigen determinant of M. bovis BCG. Further investigation of other multilateral players in immunity would be applauded.

\section{Acknowledgements}

We thank Dr. Ichiro Azuma for his advice on the preparation of BCG-CWS. We also thank Dr. Nobuyoshi Chiba for his helpful discussion, and Ms. Yukari Ishitsubo for her assistance with the study experiments.

In conducting this study, all authors declare no potential conflicting interests. All authors are Dainippon Sumitomo Pharma employees, with the exception of Dr. Ikuya Yano who is working under a contract with Dainippon Sumitomo Pharma.

\section{References}

1 Kodama K, Higashiyama M, Takami K, Oda K, Okami J, Maeda J, Akazawa T, Matsumoto M, Seya T, Wada M, Toyoshima K. Innate immune therapy with a Bacillus Calmette-Guerin cell wall skeleton after radical surgery for non-small cell lung cancer: A case-control study. Surg Today. 2009; 39:194-200.

2. Azuma I, Ribi EE, Meyer TJ, Zbar B. Biologically active components from mycobacterial cell walls. I. Isolation and composition of cell wall skeleton and component P3. J Natl Cancer Inst. 1974; 52:95-101.

3. Matsumoto M, Seya T, Kikkawa S, et al. Interferon gamma-producing ability in blood lymphocytes of patients with lung cancer through activation of the innate immune system by BCG cell wall skeleton. Int Immunopharmacol. 2001; 1:1559-1569.

4. Hayashi D, Takii T, Fujiwara N, Fujita Y, Yano I, Yamamoto S, Kondo M, Yasuda E, Inagaki E, Kanai K, Fujiwara A, Kawarazaki A, Chiba T, Onozaki K. Comparable studies of immunostimulating activities in vitro among Mycobacterium bovis bacillus CalmetteGuerin (BCG) substrains. FEMS Immunol Med Microbiol. 2009; 56:116-128.

5. Akira S, Uematsu S, Takeuchi O. Pathogen recognition and innate immunity. Cell. 2006; 124:783-801.

6. Medzhitov R, Janeway CA, Jr. Innate immunity: The 
virtues of a nonclonal system of recognition. Cell. 1997; 91:295-298.

7. Tsuji S, Matsumoto M, Takeuchi O, Akira S, Azuma I, Hayashi A, Toyoshima K, Seya T. Maturation of human dendritic cells by cell wall skeleton of Mycobacterium bovis bacillus Calmette-Guerin: Involvement of toll-like receptors. Infect Immun. 2000; 68:6883-6890.

8. Murata M. Activation of Toll-like receptor 2 by a novel preparation of cell wall skeleton from Mycobacterium bovis BCG Tokyo (SMP-105) sufficiently enhances immune responses against tumors. Cancer Sci. 2008; 99:1435-1440

9. Brennan PJ. Structure, function, and biogenesis of the cell wall of Mycobacterium tuberculosis. Tuberculosis (Edinb). 2003; 83:91-97.

10. Ishiwata A, Akao H, Ito Y, Sunagawa M, Kusunose N, Kashiwazaki Y. Synthesis and TNF-alpha inducing activities of mycoloyl-arabinan motif of mycobacterial cell wall components. Bioorg Med Chem. 2006; 14:3049-3061.

11. Takimoto H, Maruyama H, Shimada KI, Yakabe R, Yano I, Kumazawa Y. Interferon-gamma independent formation of pulmonary granuloma in mice by injections with trehalose dimycolate (cord factor), lipoarabinomannan and phosphatidylinositol mannosides isolated from Mycobacterium tuberculosis. Clin Exp Immunol. 2006; 144:134-141.

12. Sakaguchi I, Ikeda N, Nakayama M, Kato Y, Yano I, Kaneda K. Trehalose 6,6'-dimycolate (Cord factor) enhances neovascularization through vascular endothelial growth factor production by neutrophils and macrophages. Infect Immun. 2000; 68:2043-2052.

13. Grand-Perret T, Lepoivre M, Petit JF, Lemaire G. Macrophage activation by trehalose dimycolate requirement for an expression signal in vitro for antitumoral activity; biochemical markers distinguishing primed and fully activated macrophages. Eur J Immunol. 1986; 16:332-338.

14. Means TK, Wang S, Lien E, Yoshimura A, Golenbock DT, Fenton MJ. Human toll-like receptors mediate cellular activation by Mycobacterium tuberculosis. J Immunol. 1999; 163:3920-3927.

15. Underhill DM, Ozinsky A, Hajjar AM, Stevens A, Wilson CB, Bassetti M, Aderem A. The Toll-like receptor 2 is recruited to macrophage phagosomes and discriminates between pathogens. Nature. 1999; 401:811-815.

16. Uenishi Y, Kusunose N, Yano I, Sunagawa M. Isolation and identification of arabinose mycolates of cell wall skeleton (CWS) derived from Mycobacterium bovis BCG Tokyo 172 (SMP-105). J Microbiol Methods. 2010; 80:302-305.

17. Miyauchi M, Murata M, Shibuya K, Koga-Yamakawa E, Yanagawa Y, Azuma I, Kashiwazaki Y. Phagocytosis plays a dual role in activating dendritic cells; digestive production of active Toll-like receptor ligands and cooperation with Toll-like receptor signaling. Drug Discov Ther. 2010; 4:135-143.

18. Uenishi Y, Okada T, Okabe S, Sunagawa M. Study on the cell wall skeleton derived from Mycobacterium bovis BCG Tokyo 172 (SMP-105): Establishment of preparation and analytical methods. Chem Pharm Bull (Tokyo). 2007; 55:843-582.
19. Hirschfeld M, Ma Y, Weis JH, Vogel SN, Weis JJ. Cutting edge: Repurification of lipopolysaccharide eliminates signaling through both human and murine Toll-like receptor 2. J Immunol. 2000; 165:618-622.

20. Manthey CL, Perera PY, Henricson BE, Hamilton TA, Qureshi N, Vogel SN. Endotoxin-induced early gene expression in $\mathrm{C} 3 \mathrm{H} / \mathrm{HeJ}$ (Lpsd) macrophages. J Immunol. 1994; 153:2653-2663.

21. Manthey C, Vogel S. Elimination of trace endotoxin protein from rough chemotype LPS. J Endotoxin Res. 1994; 1:84-91.

22. Takeuchi O, Hoshino K, Kawai T, Sanjo H, Takada H, Ogawa T, Takeda K, Akira S. Differential roles of TLR2 and TLR4 in recognition of gram-negative and grampositive bacterial cell wall components. Immunity. 1999; 11:443-451.

23. Hoshino K, Takeuchi O, Kawai T, Sanjo H, Ogawa T, Takeda Y, Takeda K, Akira S. Cutting edge: Toll-like receptor 4 (TLR4)-deficient mice are hyporesponsive to lipopolysaccharide: evidence for TLR4 as the Lps gene product. J Immunol. 1999; 162:3749-3752.

24. Kawai T, Adachi O, Ogawa T, Takeda K, Akira S. Unresponsiveness of MyD88-deficient mice to endotoxin. Immunity. 1999; 11:115-122.

25. Werninghaus K, Babiak A, Gross O, et al. Adjuvanticity of a synthetic cord factor analogue for subunit Mycobacterium tuberculosis vaccination requires FcR $\gamma$ Syk-Card9-dependent innate immune activation. J Exp Med. 2009; 206:89-97.

26. Jin MS, Kim SE, Heo JY, Lee ME, Kim HM, Paik SG, Lee H, Lee JO. Crystal structure of the TLR1TLR2 heterodimer induced by binding of a tri-acylated lipopeptide. Cell. 2007; 130:1071-1082.

27. Gavin AL, Hoebe K, Duong B, Ota T, Martin C, Beutler B, Nemazee D. Adjuvant-enhanced antibody responses in the absence of toll-like receptor signaling. Science. 2006; 314:1936-1938.

28. Geisel RE, Sakamoto K, Russell DG, Rhoades ER. In vivo activity of released cell wall lipids of Mycobacterium bovis bacillus Calmette-Guerin is due principally to trehalose mycolates. J Immunol. 2005; 174:5007-5015

29. Agger EM, Rosenkrands I, Hansen J, Brahimi K, Vandahl BS, Aagaard C, Werninghaus K, Kirschning C, Lang R, Christensen D, Theisen M, Follmann F, Andersen P. Cationic liposomes formulated with synthetic mycobacterial cordfactor (CAF01): A versatile adjuvant for vaccines with different immunological requirements. PLoS One. 2008; 3:e3116.

30. Ishikawa E, Ishikawa $\mathrm{T}$, Morita YS, Toyonaga $\mathrm{K}$, Yamada H, Takeuchi O, Kinoshita T, Akira S, Yoshikai Y, Yamasaki S. Direct recognition of the mycobacterial glycolipid, trehalose dimycolate, by C-type lectin Mincle. J Exp Med. 2009; 206:2879-2888.

31. Koike Y, Yoo YC, Mitobe M, Oka T, Okuma K, Tonooka S, Azuma I. Enhancing activity of mycobacterial cell-derived adjuvants on immunogenicity of recombinant human hepatitis B virus vaccine. Vaccine. 1998; 16:1982-1989.

(Received January 12, 2011; Revised May 26, 2011; Accepted June 12, 2011) 